\title{
Effects of donor and acceptor doping on dielectric and ferroelectric properties of
}

\section{$\mathrm{Ba}_{0.7} \mathrm{Ca}_{0.3} \mathrm{TiO}_{3}$ lead-free ceramics}

Panupong Jaiban $^{\mathrm{a}} *$, Anucha Watcharapasorn ${ }^{\mathrm{b}, \mathrm{c}}$, Rattikorn Yimnirun ${ }^{\mathrm{d}}$, Ruyan Guo ${ }^{\mathrm{e}}$ and Amar S. Bhalla ${ }^{\mathrm{e}}$

${ }^{a}$ Faculty of Science, Energy and Environment, King Mongkut's University of Technology North Bangkok, Rayong Campus, Rayong 21120, Thailand

${ }^{\mathrm{b}}$ Department of Physics and Materials Science, Faculty of Science, Chiang Mai University, Chiang Mai 50200, Thailand

${ }^{\mathrm{c}}$ Materials Science Research Center, Faculty of Science, Chiang Mai University, Chiang Mai 50200, Thailand

${ }^{\mathrm{d}}$ School of Physics, Institute of Science, and NANOTEC-SUT COE on Advanced Functional Nanomaterials, Suranaree University of Technology, Nakhon Ratchasima 30000, Thailand

${ }^{\mathrm{e}}$ Department of Electrical and Computer Engineering, College of Engineering, The University of Texas at San Antonio, San Antonio, Texas 78249, USA

* Corresponding author. Tel: +6689-264-2984.

E-mail address: p.jaiban@gmail.com

\begin{abstract}
$\left(\mathrm{Ba}_{0.7} \mathrm{Ca}_{0.3}\right) \mathrm{TiO}_{3}, \quad\left(\mathrm{Ba}_{0.7} \mathrm{Ca}_{0.3}\right)_{0.995} \mathrm{Ti}_{0.99} \mathrm{Nb}_{0.01} \mathrm{O}_{3}$ and $\left(\mathrm{Ba}_{0.7} \mathrm{Ca}_{0.3}\right) \mathrm{Ti}_{0.99} \mathrm{Mg}_{0.01} \mathrm{O}_{2.99}$
\end{abstract} ceramics were prepared employing a solid state sintering method. The presence of $\mathrm{Ti}^{4+}$ and structural changes were revealed by X-ray diffraction patterns and X-ray absorption spectra. Upon substitution of $\mathrm{Nb}^{5+}$ and $\mathrm{Mg}^{2+}$ ions, a decrease of the ferroelectric transition temperature near room temperature and relaxor-like features of the dielectric 
properties were observed in correlation with decreased tetragonality. The change in phase transition temperature affected significantly piezoelectricity and ferroelectricity of doped ceramics. The doping could enhance the dielectric properties near room temperature of BCT ceramic. The results here suggest that dielectric, piezoelectric and ferroelectric properties of BCT may be largely tunable by $\mathrm{Nb}$ and $\mathrm{Mg}$ dopants, and $\mathrm{BCT}$ could be an alternative material for ferroelectric devices.

Keywords: Ferroelectric; Vacancy formation; Microstructure; Crystal structure; Dielectric response

\section{Introduction}

Ferroelectric materials have a long history and play an important role in many electronic devices such as sensor, actuator and capacitor [1]. Lead zirconate titanate (PZT) system is widely used in such devices. However, its major drawback is the future environment concerns. To avoid this problem, several researches have been emphasized on developing lead-free ferroelectric materials [2-4]. Among them, $\mathrm{BaTiO}_{3}-\mathrm{CaTiO}_{3}$ (BT-CT) binary system has been developed extensively as a promising candidate for such devices [5-10]. Among BT-CT based systems, $\mathrm{Ba}_{0.85} \mathrm{Ca}_{0.15} \mathrm{Ti}_{0.90} \mathrm{Zr}_{0.10} \mathrm{O}_{3}$ (BCTZ) ceramic has showed promising piezoelectricity due to the coexistence of tetragonal and rhombohedral phases near room temperature $[5,6]$. Similarly, the presence of tetragonal and orthorhombic phases makes attractive dielectric and piezoelectric properties of $\mathrm{Ba}_{0.7} \mathrm{Ca}_{0.3} \mathrm{TiO}_{3}$ (BCT) ceramic $[10,11]$. However, the focus on BCT material is quite scarce when compared with BCTZ based systems.

It is well known that electrical properties of ferroelectric materials can be tuned by employing donor and/or acceptor substitution. The dielectric, piezoelectric and 
ferroelectric properties of BCT ceramics have been enhanced by doping with, for examples, $\mathrm{Bi}^{3+}[12], \mathrm{Fe}^{3+}[13]$ and $\mathrm{La}^{3+}[14,15]$ ions. Among dopants previously investigated, magnesium $\left(\mathrm{Mg}^{2+}\right)$ and niobium $\left(\mathrm{Nb}^{5+}\right)$ ions are widely used to modify the electrical properties of ferroelectric materials [16]. However, to date, dielectric, piezoelectric and ferroelectric properties of $\mathrm{Mg}$ - and $\mathrm{Nb}$-doped $\mathrm{BCT}$ ceramics have not yet been reported. Here, we are interested in doping donor $\left(\mathrm{Nb}^{5+}\right)$ (A-site vacancies) and acceptor $\left(\mathrm{Mg}^{2+}\right)(\mathrm{O}$-site vacancies) ions in BCT ceramic in order to modify its electrical properties. The doping content $(x \leq 0.01)$ of $\mathrm{Nb}^{5+}$ and $\mathrm{Mg}^{2+}$ ions could enhance dielectric and electrical properties of ferroelectric materials, as suggested by several previous works [17-20]. Thus, in this work, $\mathrm{Ba}_{0.7} \mathrm{Ca}_{0.3} \mathrm{TiO}_{3},\left(\mathrm{Ba}_{0.7} \mathrm{Ca}_{0.3}\right)_{1-x / 2} \mathrm{Ti}_{1-x} \mathrm{Nb}_{x} \mathrm{O}_{3}$ and $\mathrm{Ba}_{0.7} \mathrm{Ca}_{0.3} \mathrm{Ti}_{1-x} \mathrm{Mg}_{x} \mathrm{O}_{3-x}$ ceramics with $x=0.01$ were fabricated. X-ray diffraction and $\mathrm{X}$ ray absorption spectroscopy measurements were used to study their structure. Also, the dielectric, piezoelectric and ferroelectric properties relating to the crystal structure and microstructure were examined and discussed.

\section{Materials and methods}

The specimens were fabricated according to the chemical formula $\left(\mathrm{Ba}_{0.7} \mathrm{Ca}_{0.3}\right)$ $\mathrm{TiO}_{3}(\mathrm{BCT}),\left(\mathrm{Ba}_{0.7} \mathrm{Ca}_{0.3}\right)_{0.995} \mathrm{Ti}_{0.99} \mathrm{Nb}_{0.01} \mathrm{O}_{3}(\mathrm{BCT}-\mathrm{Nb})$ and $\left(\mathrm{Ba}_{0.7} \mathrm{Ca}_{0.3}\right) \mathrm{Ti}_{0.99} \mathrm{Mg}_{0.01} \mathrm{O}_{2.99}$ (BCT-Mg). The powders were prepared by using a conventional mixed-oxide method. The starting materials used in this study were $\mathrm{CaCO}_{3}$ (99.95\%, Sigma-Aldrich), $\mathrm{BaCO}_{3}$ (98.5\%, Sigma-Aldrich), $\mathrm{MgO}$ (99.99\%, Sigma-Aldrich), $\mathrm{Nb}_{2} \mathrm{O}_{5}$ (99.99\%, SigmaAldrich) and $\mathrm{TiO}_{2}$ (99.9\%, Riedel-de Haën). The oxide mixtures were ball milled in ethanol for $24 \mathrm{hrs}$, dried at $120{ }^{\circ} \mathrm{C}$ for $24 \mathrm{hrs}$ and calcined in a closed alumina crucible at $1000{ }^{\circ} \mathrm{C}$ for $2 \mathrm{hrs}$. After sieving, a few drops of $3 \mathrm{wt} \%$ PVA (polyvinyl alcohol) binders were added to the mixed powders which were subsequently pressed into pellets 
with a diameter of $15 \mathrm{~mm}$ using a uniaxial press with 1.5-ton weight. Binder removal was carried out by heating the pellets at $500{ }^{\circ} \mathrm{C}$ for $1 \mathrm{hr}$. These pellets were then sintered at $1350{ }^{\circ} \mathrm{C}$ for $4 \mathrm{hrs}$ of dwell time with a heating/cooling rate of $5{ }^{\circ} \mathrm{C} / \mathrm{min}$ on a covered alumina plate.

Phase identification of the sintered specimens was investigated in 2-theta range of $20-60^{\circ}$ using an X-ray diffractometer (Miniflex, Rigaku). Then, structural refinement was carried out using MAUD 2.33 Rietveld software [21]. The local structure was studied by Synchrotron X-ray Absorption Spectroscopy (XAS) measurements conducted at ambient temperature at the BL-5.2 of the Siam Photon Laboratory, Synchrotron Light Research Institute (SLRI), Thailand, with electron energy of $1.2 \mathrm{GeV}$ and beam current 120-80 mA. The double crystal monochromator Ge (220) was used to select the energy of the X-ray beam for the Ti K-edge measurements. The experiments were carried out in a fluorescence mode and the signals were collected by using the 13component Ge-detector. For electrical property measurements, the sintered ceramics with diameter of $15 \mathrm{~mm}$ were polished in order to decrease thickness of the sample to $\sim 1 \mathrm{~mm}$. After obtaining the desired thickness, silver electrodes were coated on both surfaces of the polished ceramics. Agilent B4262 LCR-meter was used to measure dielectric properties of the samples at frequency of 1 to $100 \mathrm{kHz}$ as a function of temperature. For piezoelectric measurement, the samples were poled in silicone oil bath under a DC electric field of $6-12 \mathrm{kV} / \mathrm{cm}$ for $30 \mathrm{~min}$ and then a piezoelectric coefficient was measured using a quasistatic $d_{33}$ testing meter. The planar electromechanical coupling coefficient were determined by a resonance-antiresonance method employing 4284A LCR-meter. Ferroelectric hysteresis loop of each sample was obtained using a computer controlled modified Sawyer-Tower circuit. The electric field was applied to 
the samples by a high voltage AC amplifier at $20 \mathrm{kV} / \mathrm{cm}$. The polarization electric field $(P-E)$ loop was then recorded by a digital oscilloscope.

\section{Results and discussion}

X-ray diffraction patterns of all ceramics are shown in Fig. 1(a). Coexistence of tetragonal and orthorhombic phases can be observed for all samples, in agreement with previous works [10-15]. Beside the phase coexistence, a starting phase of $\mathrm{CaCO}_{3}$ (No. 003-0569) is also seen in BCT ceramic. However, with doping, the absence of extra phase indicates enhancement of phase purity and a complete solubility of all dopants in BCT ceramic. Upon doping, X-ray diffraction peaks shifted to lower diffraction angle due to $\mathrm{Ti}^{4+}$ ions $(0.605 \AA)$ at B-site being substituted by larger ions of $\mathrm{Mg}^{2+}(0.72 \AA)$ and $\mathrm{Nb}^{5+}(0.64 \AA$ ) [22] (see Fig. 1(b)). Beside the shift in XRD patterns, the doping affects significantly the characteristic splitting of (002) and (200) peaks, which corresponds to tetragonality of all ceramics. Interestingly, in case of BCT-Mg, the split peaks seem to merge into a single peak, indicating the structure at room temperature close to cubic phase as suggested by Isohama et al [23]. Moreover, Fig. 1 also shows the structural refinement of $\mathrm{BCT}-\mathrm{Nb}$ and $\mathrm{BCT}-\mathrm{Mg}$. In the refinement, the observed and calculated patterns are represented by black dots and red solid line, respectively. The comparison between the lattice parameters extracted from structural refinement of doping composition and the lattice values of BCT ceramic $[14,15]$ is also plotted in Fig. 1(c). From this result, it can be seen that after doping with $\mathrm{Nb}$, both a- and c-axes are extended. In case of BCT-Mg, a- and c- axes are almost similar so its lattice becomes closer to cubic. Nevertheless, the overall change in lattice parameters in $\mathrm{Nb}$ - and $\mathrm{Mg}$ doped BCT causes an increase in the unit cell volume in agreement with the B-site substitution by larger dopants. 
For further investigation of local structure related to lattice change and site substitution, we employed Synchrotron X-ray Absorption Spectroscopy (XAS) technique to obtain local structure information around $\mathrm{Ti}$ atoms. The results on normalized Ti K-edge X-ray Absorption Near-Edge Structure (XANES) spectra for doped ceramics are compared to BCT ceramic as shown in Fig. 2 (a) for BCT-Nb and (b) for BCT-Mg. The excited energy $\left(E_{0}\right)$ for all ceramics is about $4985 \mathrm{eV}$, close to $E_{0}$ of the $\mathrm{TiO}_{2}$ standard. These results reveal that oxidation state of $\mathrm{Ti}$ ions in these samples is equal to +4 . Beside the existence of $\mathrm{Ti}^{4+}$, the decreasing intensity of $\mathrm{Ti} \mathrm{K}$ pre-edge XANES spectra (marked as peak $\mathrm{A}$ in insets) associate with the electron transition of $\mathrm{Ti}$ from $1 \mathrm{~s}$ to $3 \mathrm{~d}$ state [24] can be noticeable in doped samples. This indicates the decrease of Ti off-centering, which relates to weakness of ferroelectric polar in doped ceramics.

Microstructural images of all ceramics are illustrated in Fig. 3. It can be seen that BCT grains are largest (see Fig. 3(a)). Upon the doping as shown in Fig. 3(b) for BCT$\mathrm{Nb}$ and (c) for BCT-Mg, the grain size becomes smaller. The influences of A-site cation vacancies and oxygen vacancies produced by the electronic compensation mechanism in terms of Kröger and Vink notation [25] for donor $\left(T i_{T i}^{x} \rightarrow 2 N b_{T i}^{\cdot}+V_{B a / C a}^{\prime \prime}\right)$ and acceptor $\left(T i_{T i}^{x} \rightarrow M g_{T i}^{\prime \prime}+V_{O}^{*}\right)$ substitutions should play a major role in the decreasing trend of these grains. With this phenomenon, these vacancies exist along grain boundaries, which is thermodynamically more stable, rather than inside grain. Grain boundaries would be pinned by these defects, inhibiting grain growth and resulting in relatively small grains $[19,26]$. The quantitative detail of grain sizes extracted from their microstructural images is shown in Fig. 3(d). 
Figure 4 displays the dielectric constant and dielectric loss as a function of temperature at various frequencies for all ceramics. As seen in Fig. 4(a), BCT ceramic shows a sharp phase transition from ferroelectric to paraelectric and a frequency independence of the maximum relative permittivity, suggesting a normal ferroelectric behavior in this sample. For the donor-doped sample (BCT-Nb) (Fig. 4(b)), the feature of the dielectric behavior with increasing temperature is not significantly different from that of BCT. However, in case of acceptor doping (BNT-Mg), the phase transition becomes more diffuse as shown in Fig. 4(c). The dielectric constant comparison of all ceramics at frequency of $1 \mathrm{kHz}$ is shown in Fig. 4(d). The result shows that aliovalent doping has apparent effects on the dielectric properties of BCT. It should be mentioned first that the high-temperature dielectric behavior is attributed mainly to domain wall motion. Thus, better mobility of domain wall gives higher value of maximum dielectric constant $\left(\varepsilon_{\mathrm{m}}\right)$. In case of the ceramics under investigation, smaller grains retard the movement of ferroelectric domain; thus, $\varepsilon_{\mathrm{m}}$ of doped ceramics becomes lower. The decreasing $\varepsilon_{\mathrm{m}}$ values accompanied the decreasing trend of their grain sizes in Fig. 3(d). Beside the decrease of $\varepsilon_{\mathrm{m}}$, the permittivity of doped ceramics can be enhanced near room temperature since the decreasing of the temperature $\left(T_{\mathrm{m}}\right)$ where maximum dielectric exists (see quantitative data in Table 1). Regarding the decrease of $T_{\mathrm{m}}$, particularly for BCT-Mg, it can be attributed to its structural distortion closer to cubic lattice near room temperature (in Fig. 1(c)). Beside the change in dielectric properties of BCT ceramic, the doping affects significantly piezoelectric properties of BCT ceramic. In Fig. 4(e) and (f), it can be seen that BCT ceramic presents highest piezoelectric coefficient $\left(d_{33}\right)$ and planar electromechanical coupling factor $\left(k_{\mathrm{p}}\right)$. The values decrease after $\mathrm{Nb}$ and $\mathrm{Mg}$ doping. Interestingly, the linear relationship between the decrease of 
piezoelectric properties and the change in dielectric properties i.e. decrease of $T_{\mathrm{m}}$ is observed in these ceramics. From the result, it is believed that the existence of cubiclike structure producing spontaneous polarization weakness should play an important role for decrease of $d_{33}$ and $k_{\mathrm{p}}$ values of doped ceramics, particularly BCT-Mg. Thus, with these measurements, the dielectric and piezoelectric properties of BCT can be tuned by $\mathrm{Nb}$ and $\mathrm{Mg}$ doping through reduction of $T_{\mathrm{m}}$.

An inverse of the relative permittivity $\left(1 / \varepsilon_{\mathrm{r}}\right)$ as a function of a temperature at 1 $\mathrm{kHz}$ is plotted in Fig. 5 to explain further the dielectric phenomenon in these ceramics by Curie-Weiss law, which describes the ferroelectric transition into the paraelectric region and is expressed as

$$
\frac{1}{\varepsilon}=\frac{T-T_{C}}{C}
$$

where $T_{\mathrm{C}}$ is Curie temperature and $\mathrm{C}$ is the Curie-Weiss constant [27]. The linear fitting is examined in paraelectric region (i.e. above $T_{\mathrm{C}}$ ). The fitting parameters, i.e. the Curie temperature and Curie-Weiss constant, are listed in Table 1. Based on the fitting analysis, BCT ceramic shows maximum $T_{\mathrm{C}} \sim 100{ }^{\circ} \mathrm{C}$ (Fig. 5(a)). Upon doping, the phase transition temperature from ferroelectric to paraelectric state decreases and becomes much lower for BCT-Mg $\sim 75{ }^{\circ} \mathrm{C}$ (see in Fig. 5(c)). With the observed decrease of $T_{\mathrm{C}}$, we summarize the linear relationship between the tetragonality and $T_{\mathrm{C}}$ in Fig. $5(\mathrm{~d})$. Especially with $\mathrm{Mg}$ doping, the structure becomes closer to cubic and this causes an apparent decrease of $T_{\mathrm{C}}$ due to the favorability of the paraelectric phase transformation at lower temperature. 
Besides the change in $T_{\mathrm{C}}$, the diffuse characteristics of ferroelectric-paraelectric phase transition known to deviate from the typical Curie-Weiss behavior could be described by a modified Curie-Weiss relationship [28]:

$$
\frac{1}{\varepsilon_{r}}-\frac{1}{\varepsilon_{m}}=\frac{\left(T-T_{m}\right)^{\gamma}}{C},
$$

where $\gamma$ and $\mathrm{C}$ are assumed to be constant. The parameter $\gamma$ gives information on the character of the phase transition: for $\gamma=1$, a normal ferroelectric in which Curie-Weiss law is obeyed, $\gamma=2$ describes a complete diffuse phase transition suggesting the relaxor behavior [28]. Plots of $\ln \left(\frac{1}{\varepsilon_{r}}-\frac{1}{\varepsilon_{m}}\right)$ as a function of $\ln \left(T-T_{m}\right)$ for these ceramics at frequency of $1 \mathrm{kHz}$ are displayed as insets in Fig. 5. The $\gamma$ value of BCT ceramic listed in Table 1 is found to fall in the normal ferroelectric side $(\gamma=1)$, indicating the normal ferroelectricity of this system. Upon doping, $\gamma$ values change clearly from 1.12 to 1.35 for $\mathrm{BCT}-\mathrm{Nb}$ and to 1.52 for $\mathrm{BCT}-\mathrm{Mg}$. This reflects that dielectric response of doped ceramics moves more towards relaxor-like behavior (i.e. more diffuse phase transition). The contribution may be due to the site vacancies. Thus, with this result, $\mathrm{Nb}$ and $\mathrm{Mg}$ doping can induce the characteristic of diffuse phase transition in BCT ceramic.

$P-E$ hysteresis loops as a function of temperature for all ceramics are illustrated in Fig. 6 (a) for $\mathrm{BCT}$, (b) for $\mathrm{BCT}-\mathrm{Nb}$ and (c) for $\mathrm{BCT}-\mathrm{Mg}$, respectively. At the temperature below $T_{\mathrm{m}}$, the normal ferroelectric characteristic of $P-E$ loops is observed. With increasing temperature above $T_{\mathrm{m}}$, the $P-E$ loop feature becomes slimmer, resulted from the increased contribution of paraelectric phase. This observation is in agreement with dielectric measurements of these ceramics (Fig. 4 and 5). Beside ferroelectricity as a function of the temperature, we also show $P-E$ loops at room temperature as insets for 
each ceramic. The $P-E$ loops in correlation with tetragonality of all ceramics can be seen clearly. Figure 6(d) displays the influences of dopant on remanent polarization $\left(P_{\mathrm{r}}\right)$ and coercive field $\left(E_{c}\right)$, extracted from $P$-E loops. As observed, both $P_{\mathrm{r}}$ and $E_{c}$ values decrease gradually for BCT-Nb. Nevertheless, in case of BCT-Mg, the values become much lower. Due to the cubic-like structure inducing a weak spontaneous ferroelectric polarization, the low tetragonality of this ceramic seems to be main reason for decrease of these values. Beside structural feature of these ceramics, an additional cause is likely from more diffuse phase transition behavior in doped ceramics. Also, the observed ferroelectricity i.e. decrease of $P_{\mathrm{r}}$ and $E_{c}$ values is associated well with their piezoelectric properties.

\section{Conclusion}

In this work, BCT, BCT-Nb (A-site vacancies) and BCT-Mg (O-site vacancies) ceramics were fabricated using a solid state sintering process. Upon the aliovalent doping, the decrease of the ferroelectric phase transition temperature near room temperature and the diffused relaxor-like features of the dielectric are observed in association with the decrease of tetragonality. The change in phase transition temperature plays a major role in decreasing of piezoelectricity and ferroelectricity of BCT ceramics. Although the phase transition temperature becomes lower, the dielectric properties of BCT material near room temperature can be enhanced with these dopants. Therefore, it is suggested that $\mathrm{Nb}$ and $\mathrm{Mg}$ ion substitutions can be useful for tuning the dielectric, piezoelectric and ferroelectric properties of BCT materials which may find future application in ferroelectric devices.

\section{Acknowledgements}


This research was funded by King Mongkut's University of Technology North Bangkok. Contract no. KMUTNB-ART-60-17.

\section{References}

[1] A.S. Bhalla, R. Guo, R. Roy, The perovskite structure - a review of its role in ceramic science and technology, Mat. Res. Innovat. 4 (2000) 3-26.

[2] J. Rödel, W. Jo, K.T.P. Seifert, E.M. Anton, T. Granzow, D. Damjanovic, Perspective on the development of lead-free piezoceramics, J. Am. Ceram. Soc. 92[2] (2009) 1153-1177.

[3] J. Wu, D. Xiao, J. Zhu, Potassium-sodium niobate lead-free piezoelectric materials: part, present, and future of phase boundaries, Chem. Rev. 115 (2015) 25592595.

[4] X. Wang, J. Wu, D. Xiao, J. Zhu, X. Cheng, T. Zheng, B. Zhang, X. Lou, X. Wang, Giant piezoelectricity in potassium-sodium niobate lead-free ceramics, J. Am. Chem. Soc. 136 (2014) 2905-2910.

[5] J. Wu, D. Xiao, W. Wu, Q. Chen, J. Zhu, Z. Yang, J. Wang, Compotition and poling condition-induced electrical behavior of $\left(\mathrm{Ba}_{0.85} \mathrm{Ca}_{0.15}\right) \mathrm{Ti}_{1-x} \mathrm{Zr}_{x} \mathrm{O}_{3}$ lead-free piezoelectric ceramics, J. Eur. Ceram. Soc. 32 (2012) 891-898.

[6] J. Wu, D. Xiao, W. Wu, Q. Chen, J. Zhu, Z. Yang, J. Wang, Role of roomtemperature phase transition in the electrical properties of $(\mathrm{Ba}, \mathrm{Ca})(\mathrm{Ti}, \mathrm{Zr}) \mathrm{O}_{3}$ ceramics, Scr. Mater. 65 (2011) 771-774.

[7] X.N. Zhu, W. Zhang, X.M. Chen, Enhanced dielectric and ferroelectric characteristics in Ca-modified $\mathrm{BaTiO}_{3}$ ceramics, AIP Adv. 3 (2013) 082125. 
[8] D. Fu, M. Itoh, S.Y. Koshihara, T. Kosugi, S. Tsuneyuki, Anomalous phase diagram of ferroelectric $(\mathrm{Ba}, \mathrm{Ca}) \mathrm{TiO}_{3}$ single crystals with giant electromechanical response, Phys. Rev. Lett. 100 (2008) 227601.

[9] I. Levin, V. Krayzman, J.C. Woicik, Local-structure origins of the sustained Curie temperature in $(\mathrm{Ba}, \mathrm{Ca}) \mathrm{TiO}_{3}$ ferroelectrics. Appl. Phys. Lett. 102 (2013) 162906.

[10] R.C. Pullar, Y. Zhang, L. Chen, S. Yang, J.R.G. Evans, A.N. Salak, D.A. Kiselev, A.L. Kholkin, V.M. Ferreira, N.M. Alford, Dielectric measurements on a novel $\mathrm{Ba}_{1-x} \mathrm{Ca}_{x} \mathrm{TiO}_{3}$ (BCT) bulk ceramic conbinatorial library, J. Electroceram. 22 (2009) 245251.

[11] C.X. Li, B. Yang, S.T. Zhang, R. Zhang, W.W. Cao, Effects of sintering and poling conditions on the electricl properties of $\mathrm{Ba}_{0.70} \mathrm{Ca}_{0.30} \mathrm{TiO}_{3}$ diphasic piezoelectric ceramics, Ceram. Int. 39 (2013) 2967-2973.

[12] S. Yun, X. Wang, J. Shi, J. Zhu, D. Xu, Ferroelectric properties of barium calcium titanate ceramics doped with bismuth oxide, Mater. Lett. 63 (2009) 1883-1885.

[13] C.X. Li, B. Yang, S.T. Zhang, R. Zhang, Y. Sun, J.J. Wang, R.X. Wang, W.W. Cao, Phase transition, microstructure and electrical properties of $\mathrm{Fe}$ doped $\mathrm{Ba}_{0.7} \mathrm{Ca}_{0.3} \mathrm{TiO}_{3}$ lead-free piezoelectric ceramics, Ceram. Int. 39 (2013) 8701-8708.

[14] P. Jaiban, S. Suwanwong, O. Namsar, A. Watcharapasorn, W. Meevasana, Simultaneous tuning of the dielectric property and photo-induced conductivity in ferroelectric $\mathrm{Ba}_{0.7} \mathrm{Ca}_{0.3} \mathrm{TiO}_{3}$ via La doping, Mater. Lett. 147 (2015) 29-33. 
[15] P. Jaiban, O. Namsar, S. Jiansirisomboon, A. Watcharapasorn, R. Yimnirun, Electrical properties of La-doped $\mathrm{Ba}_{0.7} \mathrm{Ca}_{0.3} \mathrm{TiO}_{3}$ lead-free ceramics, Ferroelectrics 487 (2015) 86-93.

[16] T.R. Shrout, S.J. Zhang, Lead-free piezoelectric ceramics: Alternatives for PZT? J. Electroceram. 19 (2007) 111-124.

[17] T. Wang, L. Jin, Y. Tian, L. Shu, Q. Hu, X. Wei, Microstructure and ferroelectric properties of $\mathrm{Nb}_{2} \mathrm{O}_{5}$-modified $\mathrm{BiFeO}_{3}-\mathrm{BaTiO}_{3}$ lead-free ceramics for energy storage, Mater. Lett. 137 (2014) 79-81.

[18] M. Li, L. Li, J. Zang, D.C. Sinclair, Donor-doping and reduced leakage current in $\mathrm{Nb}$-doped $\mathrm{Na}_{0.5} \mathrm{Bi}_{0.5} \mathrm{TiO}_{3}$, Appl. Phys. Lett. 106 (2015) 102904.

[19] J. Miao, Z. Zhang, Z. Liu, Y. Li, Investigation on the dielectric properties of Mg-doped $\left(\mathrm{Ba}_{0.95} \mathrm{Ca}_{0.05}\right)\left(\mathrm{Ti}_{0.85} \mathrm{Zr}_{0.15}\right) \mathrm{O}_{3}$ ceramics, Ceram. Int. 41 (2015) S487-491.

[20] B. Su, T.W. Button, Microstructure and dielectric properties of Mg-doped barium strontium titanate ceramics, J. Appl. Phys. 95[3] (2004).

[21] L. Lutterotti, D. Chateigner, S. Ferrari, J. Ricote, Texture, residual stress and structure analysis of thin films using a combined X-ray analysis. Thin Solid Films 450 (2004) 34-41.

[22] R.D. Shannon, Revised effective ionic radii and systematic studies of interatomic distance in halides and chalcogenides, Accta. Cryst. A32 (1976) 751-767.

[23] Y. Isohama, N. Nakajima, H. Maruyama, Y. Tezuka, T. Iwazumi, Tetragonalcubic phase transition in $\mathrm{BaTiO}_{3}$ probed by resonant X-ray emission spectroscopy, J. Electron. Spectrosc. Relat. Phenom. 184 (2011) 207-209. 
[24] B. Ravel, E.A. Stern, R.I. Vedrinskii, V. Kraizman, Local structure and the phase transitions of $\mathrm{BaTiO}_{3}$, Ferroelectrics 206 (1998) 407-430.

[25] F.A. Kröger, H.J. Vink, Relations between the concentrations of imperfections in crystalline solids, Solid State Phys. 3 (1956) 307-335.

[26] N. Petnoi, P. Bomlai, S. Jiansirisomboon, A. Watcharapasorn, Effects of Nbdoping on the micro-structure and dielectric properties of $\left(\mathrm{Bi}_{0.5} \mathrm{Na}_{0.5}\right) \mathrm{TiO}_{3}$ ceramics, Ceram. Int. 39 (2013) S113-117.

[27] T. Maiti, R. Guo, A.S. Bhalla, The evolution of relaxor behavior in $\mathrm{Ti}^{4+}$ doped $\mathrm{BaZrO}_{3}$ ceramics, J. Appl. Phys. 100 (2006) 114109.

[28] Y. Zhen, J.F. Li, Normal sintering of $(\mathrm{K}, \mathrm{Na}) \mathrm{NbO}_{3}$-based ceramic: influence of sintering temperature on densification, microstructure, and electrical properties, J. Am. Ceram. Soc. 89 (2006) 3669-3675. 


\section{Figure captons}

Figure 1 Phase indenfications when $(a)=X R D$ patterns of all ceramics, $(b)=X R D$ patterns in the 2-theta range of $30^{\circ}-35^{\circ}$ and $(c)=$ the change in lattice parameter and cell volume of all ceramics.

Figure 2 Comparison of the normalized X-ray absorption Ti K-edge spectra between BCT and doped ceramics $(\mathrm{a})=\mathrm{BCT}-\mathrm{Nb}$ and $(\mathrm{b})=\mathrm{BCT}-\mathrm{Mg}$.

Figure 3 Microstructural images of all ceramics $(\mathrm{a})=\mathrm{BCT},(\mathrm{b})=\mathrm{BCT}-\mathrm{Nb},(\mathrm{c})=\mathrm{BCT}-$ $\mathrm{Mg}$ and $(\mathrm{d})=$ relationship between grain size and the doping.

Figure 4 Relationship between $\varepsilon_{\mathrm{r}}$ and $\tan \delta$ as a function of the temperature of all ceramics from 1 to $100 \mathrm{kHz}$, (a) = BCT, (b) = BCT-Nb, (c) $=\mathrm{BCT}-\mathrm{Mg}$, (d) $=$ comparison of $\varepsilon_{\mathrm{r}}$ for all ceramics at $1 \mathrm{kHz},(\mathrm{e})$ and (f) $=$ relationship between $d_{33}$ and $k_{\mathrm{p}}$ and $T_{\mathrm{m}}$ of all ceramics, respectively.

Figure 5 The inverse of $\varepsilon_{\mathrm{r}}\left(1 / \varepsilon_{\mathrm{r}}\right)$ as a function of the temperature at $1 \mathrm{kHz}(\mathrm{a})=\mathrm{BCT}$, (b) = BCT-Nb and (c) = BCT-Mg. The insets are plots of $\ln \left(\frac{1}{\varepsilon_{r}}-\frac{1}{\varepsilon_{m}}\right)$ as a function of $\ln \left(T-T_{m}\right)$ for all ceramics. (d) = relationship between tetragonality (c/a) and $T_{\mathrm{C}}$ of all ceramics.

Figure 6 Relationship between $P-E$ loops as a function of the temperature of all ceramics $(\mathrm{a})=\mathrm{BCT},(\mathrm{b})=\mathrm{BCT}-\mathrm{Nb}$ and $(\mathrm{c})=\mathrm{BCT}-\mathrm{Mg}$, insets are $P-E$ loops at room temperature. $(\mathrm{d})=P_{\mathrm{r}}$ and $E_{\mathrm{c}}$ values of all ceramics. 
Figure 1
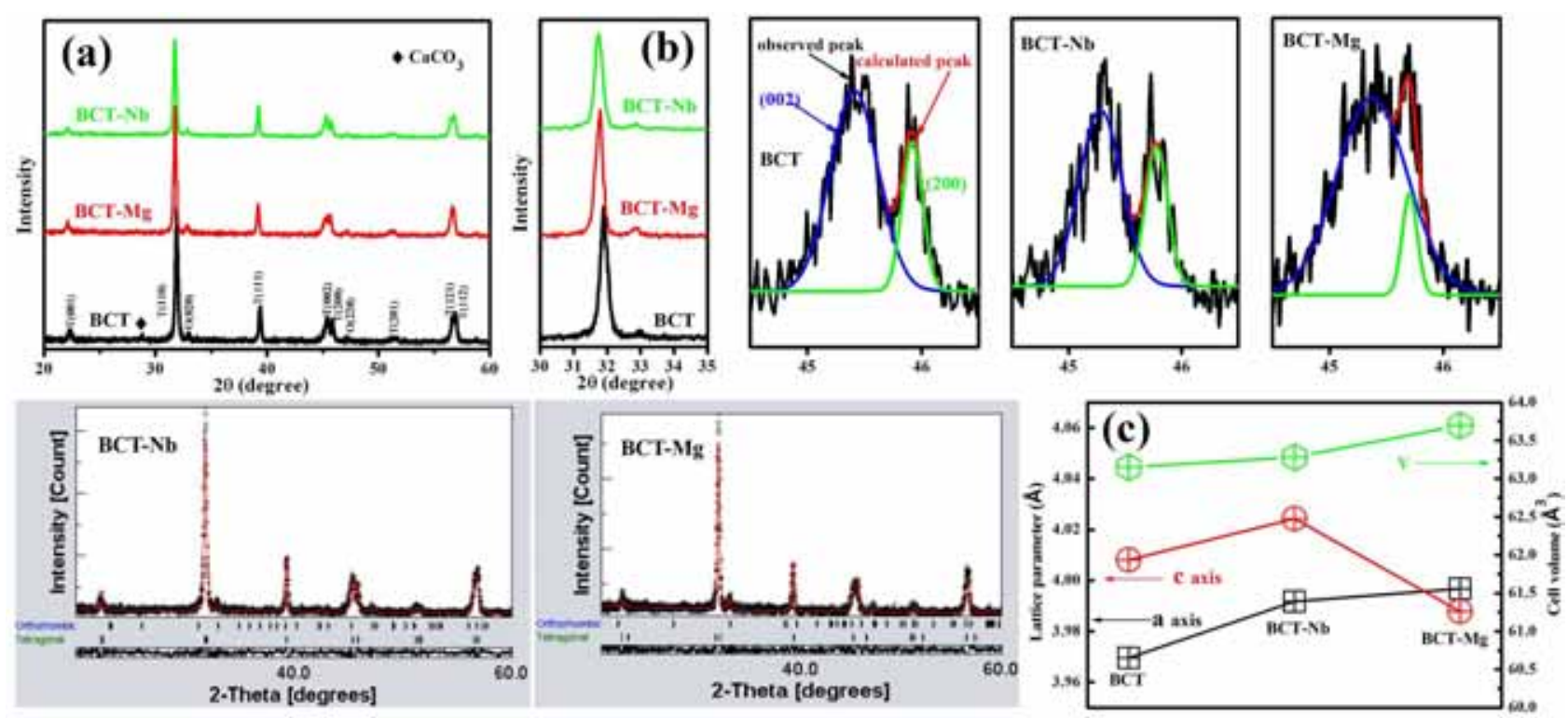

Figure 2
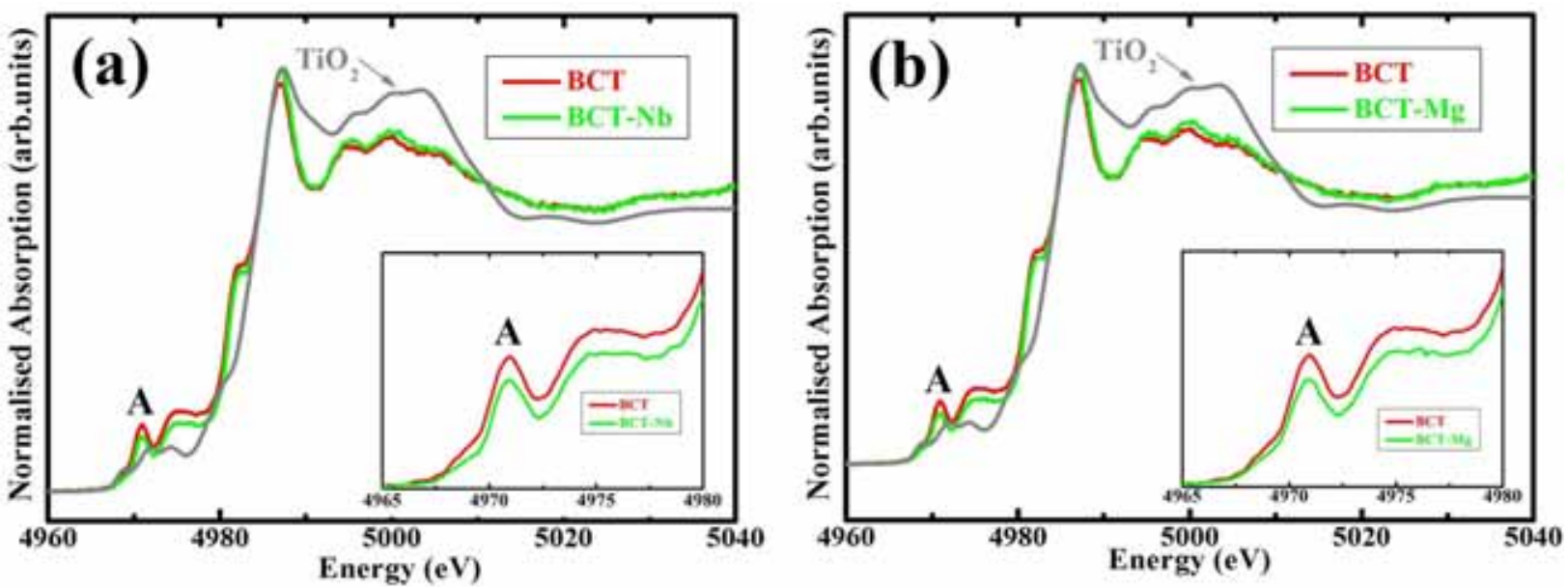
Figure 3

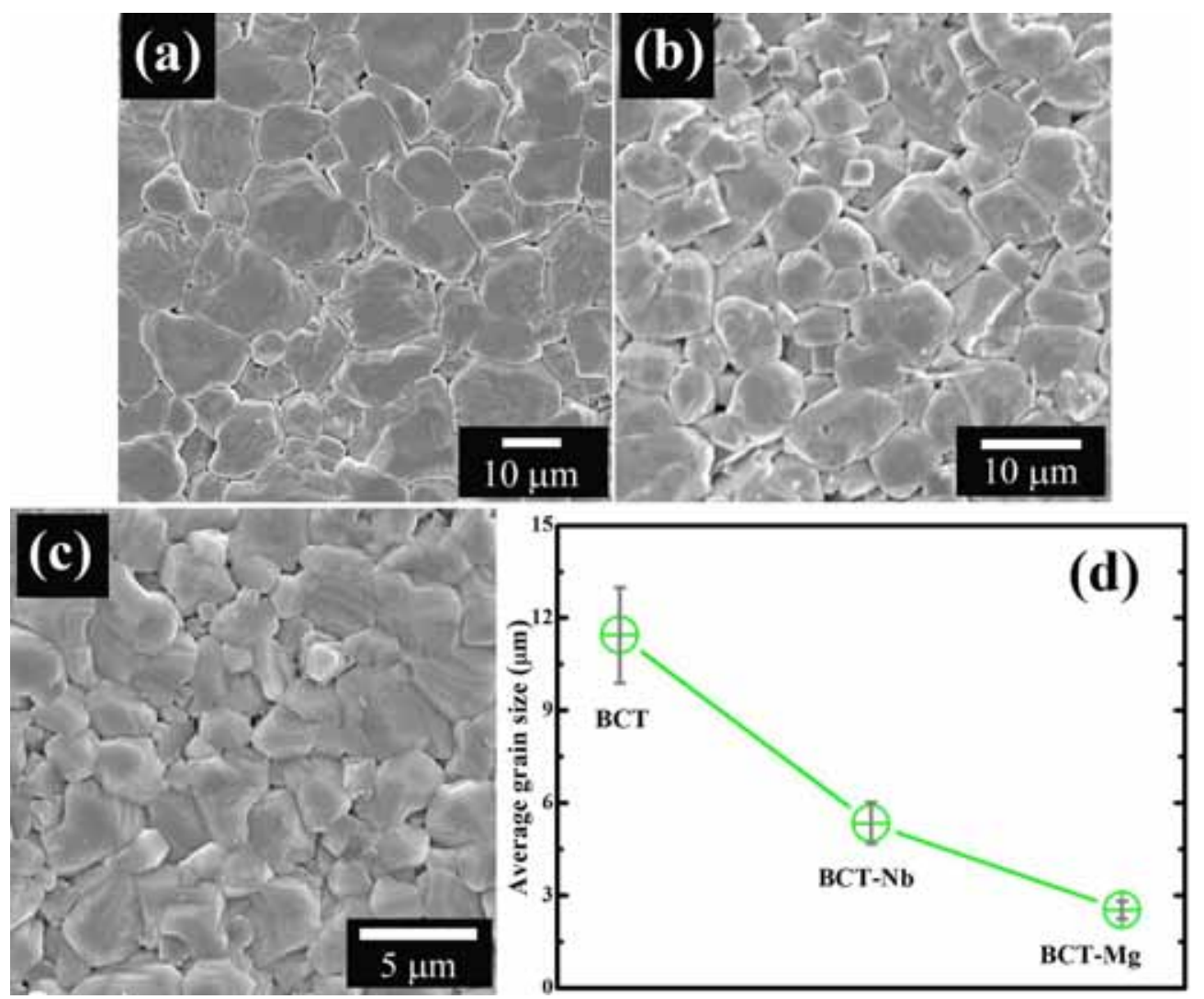


Figure 4
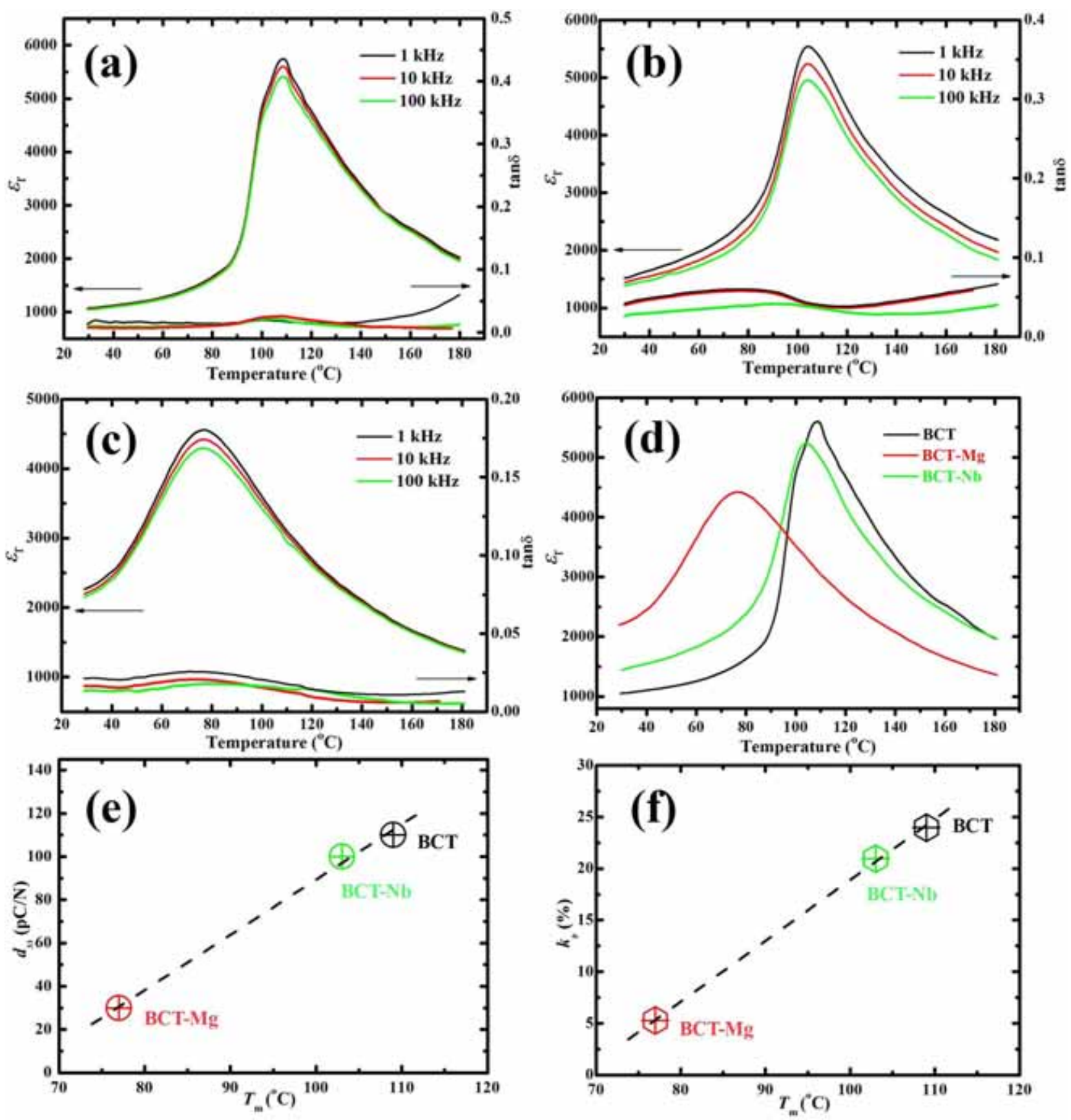
Figure 5
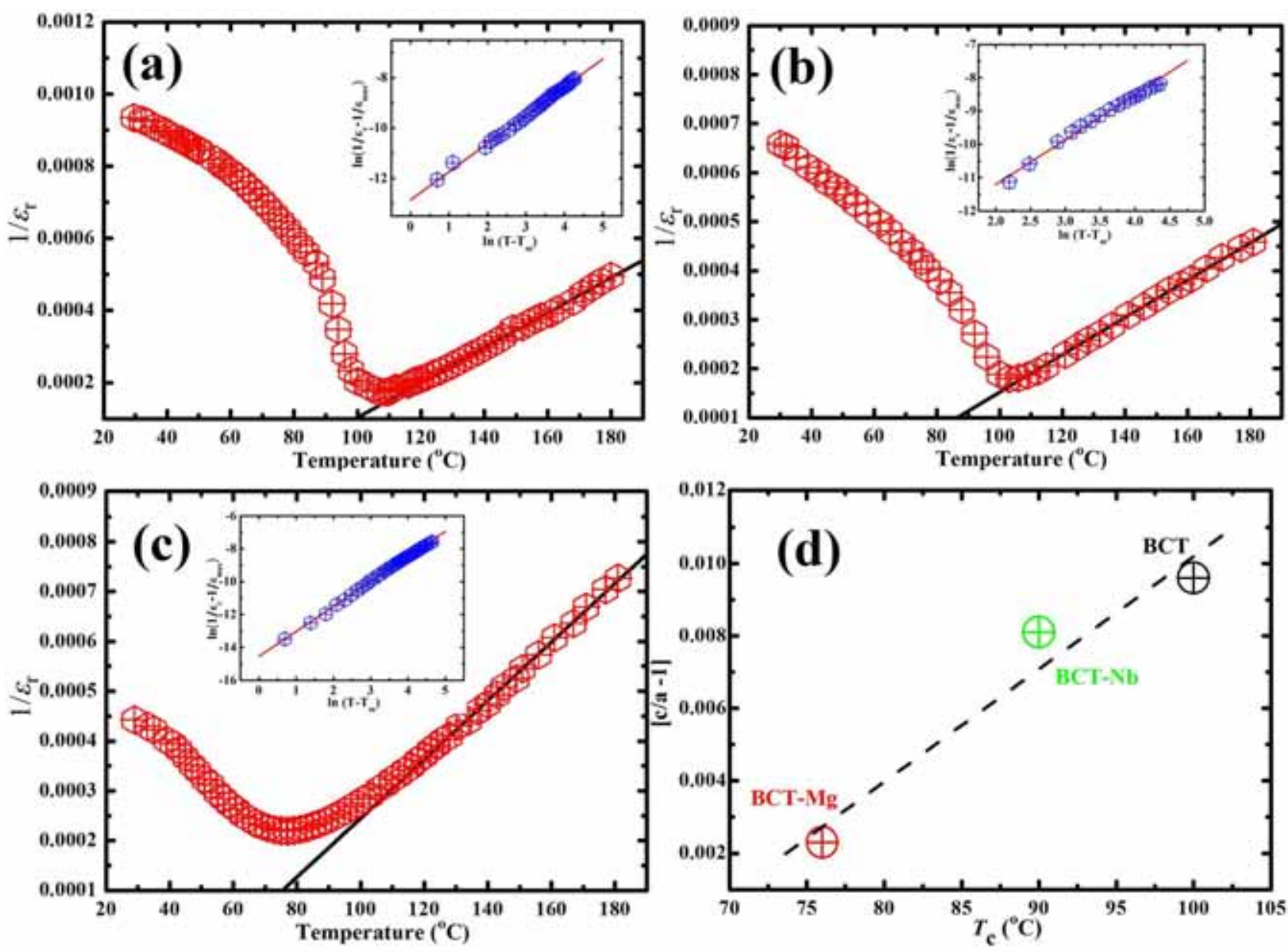
Figure 6
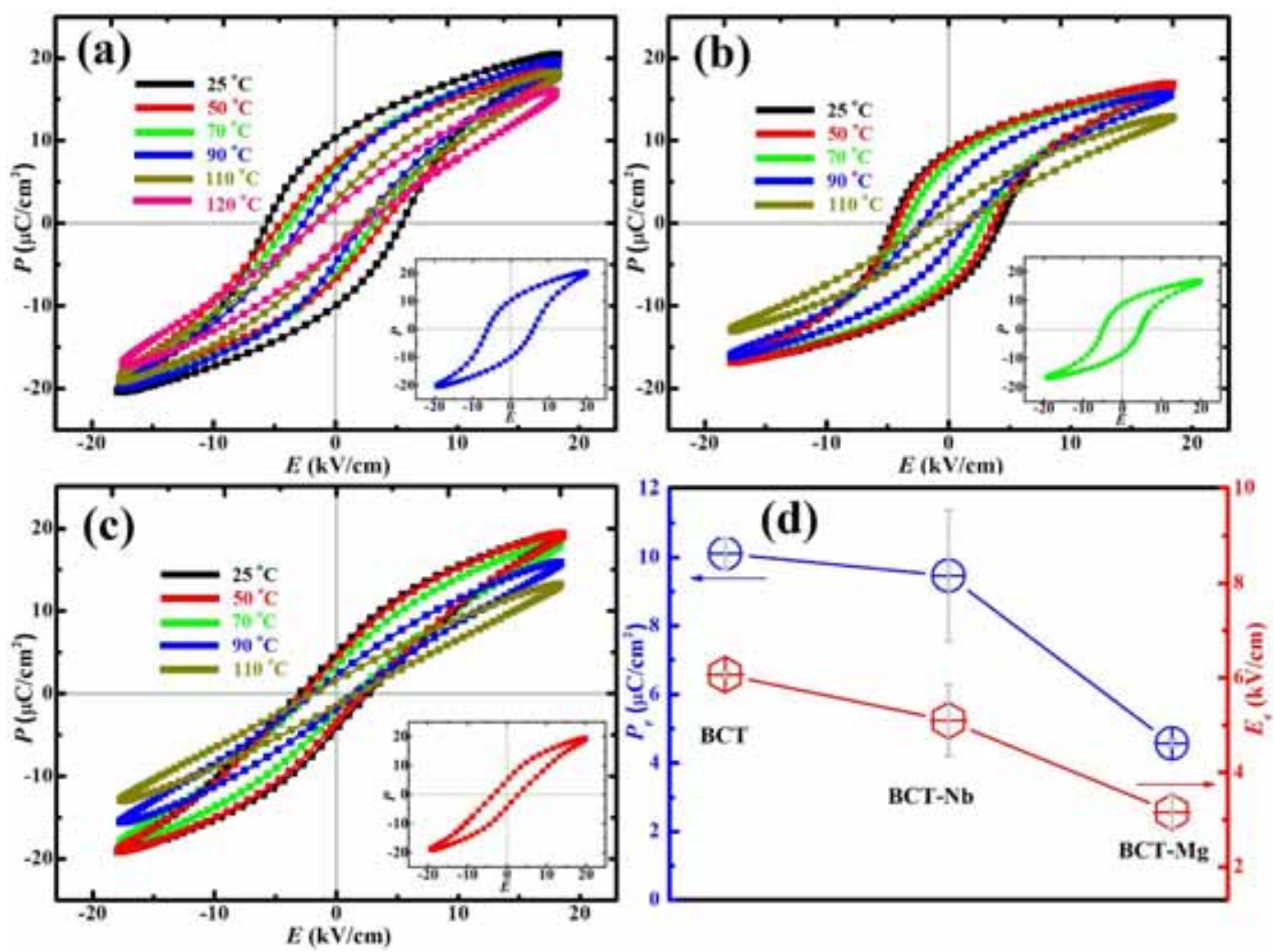
Table 1 Dielectric properties of all ceramics at $1 \mathrm{kHz}$

\begin{tabular}{cccccccc}
\hline ceramics & $\mathrm{C}\left({ }^{\circ} \mathrm{C}\right)$ & $T_{\mathrm{c}}\left({ }^{\circ} \mathrm{C}\right)$ & $\gamma$ & $\varepsilon_{\mathrm{r}}$ & $\tan \delta$ & $\varepsilon_{\mathrm{m}}$ & $T_{\mathrm{m}}\left({ }^{\circ} \mathrm{C}\right)$ \\
\hline BCT & $2.06 \times 10^{5}$ & 100 & 1.12 & 1070 & 0.01 & 5752 & 109 \\
BCT-Nb & $2.62 \times 10^{5}$ & 90 & 1.35 & 1519 & 0.04 & 5573 & 103 \\
BCT-Mg & $1.69 \times 10^{5}$ & 75 & 1.52 & 2261 & 0.02 & 4567 & 77 \\
\hline
\end{tabular}




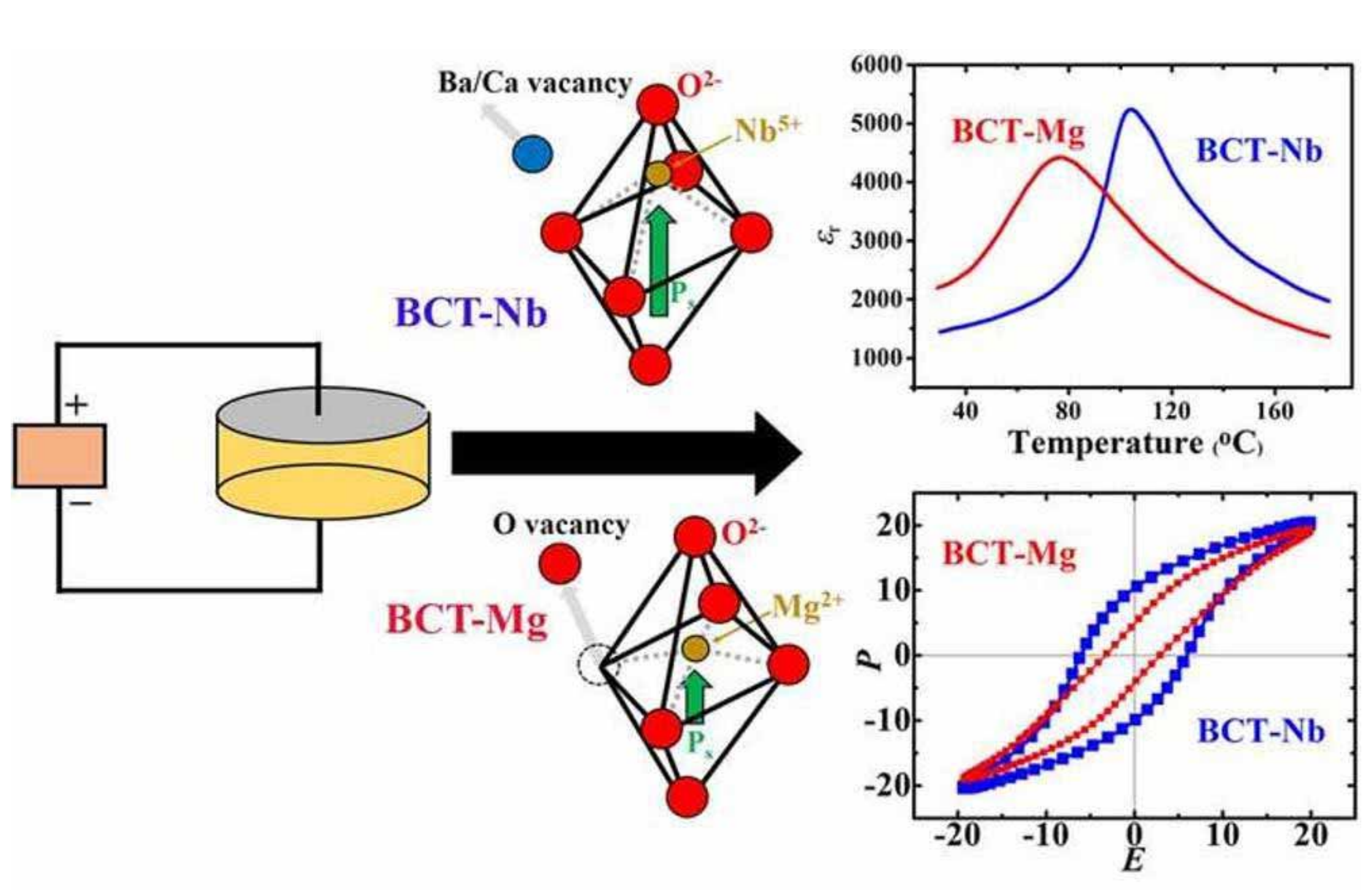

